\title{
Discurso do Sr. Ministro Rogério de Freitas ao entregar os Anais (com 7 cartas)
}

\author{
DISCLIRSO D $\because$ MINISTRO ROGERIO DE FREITAS AO ENTREGAR \\ AO T. C. OS ANAIS DO CONGRESSO
}

Senhor Ministro Presidente:

$E^{\prime}$ com a maior satisfação e com justificado orgulho que transmito a V. Exa. e aos digníssimos senhores Ministros, em absoluta prioridade, os Anais do $3^{\circ}$ Congresso Internacional das Instituições de Contrôle das Finanças Públicas.

A escolha do Brasil para sede do $3^{\circ}$ Congresso foi feita por aclamação, durante a sessão plenária de encerramento do $2^{\circ}$ Congresso realizado em Bruxelas, em 1956.

Aos repręentantes do Brasil, delegados dêste Tribunal, não caberia outra alternativa senão acatar e agradecer tão alta distinção, e trazê-la ao conhecimento desta Casa.

Foi o que fizemos, em sessão de 9 de agôsto de 1957, ao apresentarmos o relatório sôbre $\circ 2^{\circ}$ Congresso.

Em 16 do mesmo mês e anc, recebiamos do Sr. Presidente do Tribunal, o eminente Ministro Wergniaud WANDERLEY, o Ofício $\mathrm{n}^{\circ} 2.554$, pelo qual nos dava ciência da resolução tomada na referida sessão de 9 de agôsto, incumbindo-nos de planejar a organização e realização do 3. Congresso Internacional das Instituições de Contrôle das Finanças Públicas, o qual deveria reunir-se em 1959, nesta Capital.

A tarefa não era fácil, eis que exigia, por sua natureza e importância, um cuidadoso exarie na adoção das medidas aconselháveis ao seu przparo e realização, a fim de levá-la a tom têrmo.

Após um estudo preliminar, pareceu-nos indispensável um entendimento com o Secretariado Permanente, com sede em Havana, e, assim, para lá nos deslocamos, a convite do eminente Professor Emílıo Camus então Presidente do Tribunal de Contas de Cuba e daquele Secretariado, de cujos arquivos deveria cunstar a documentação referente às diversas Instituiģ̄ies congêneres.

De posse dos elementos ali colhidos e com designação feita por aquêle Presidente para Secretário-Executivo do $3^{\circ}$ Congresso, com delegação de 
todos os podêres para o seu planejamento e realização - cuja data foi desde logo fixada de comum acôrdo para 3 a 10 de maio dêste ano - demos início aos trabalhos preparatórios indispensáveis, a fim de evitar as improvisações tão comur:s em certames dessa natureza.

Aos mestno tempo em quie se éxpedia volumosa correspondência às entidades conhecidas, empreendemos aqui cuidadoso estudo visando à organização, sede para a realização, acomodação dos Delegados e solicitação, ao Legislativo, do crédito necessário às despesas do Congresso.

A primeira carta-circular teve como finalidade dar conhecimento às diversas Instituições das providências preliminares estabelecidas, periodo de realização do Congresso, bem como solicitar a manifestação de cada uma delas sôbre os temas que deveriam fazer parte de sua agenda.

Quarenta e oito Instifuiçẽes responderam, enviando sugestões para a Agenda do Congresso, dentre as quais as três mais interessantes foram escolhidas.

A seleção dos temas foi feita após consulta a todos os Ministros desta Côrte e, em novembro de 1958, foi comunicada às Instituições de Contrôle a Agenda aprovada, solicitando-se remessa de trabalhos nela baseados.

Em janeiro do corrente ano o Dr. Victor Amaral. Freire do Tribunal de Contas de São Paulo, o Dr. Armando De Oliveira Pinto do I.B.G.E. e c. Sr. José Mariano da Silva foram convidados para integrarem a Secretaria Executiva, nas funções de Assessor Técnico, Secretário-Executivo-Adjunto e Chefe do Serviço de Administração, respectivamente, passando a Comissão a funcionar no $14^{\circ}$ andar dêste Edifício, acrescida de outros elementus para os serviços de dactilografia, documentação, revisão, distribuição etc.

Em 10 de março seguinte foi aberto o crédito de $\operatorname{Cr} \$ 10.000 .000,00$ palo Decreto $n^{\circ} 45.563$. E em 16 seguinte, pelo Decreto $n^{\circ} 45.573$, foi oficializado o 3 s Congresso Internacional das Instituições de Contrôle das Finanças Públicas.

A Secretaria Executiva elaborou o Regulamento do Congresso e dêle deu conhecimento a tôdas as Instituições.

Com o desenvolvimento dos trabalhos, e para melhor atender às fina lidades do Congressc, dividimos as atividades em três períodos distintos:

19) Pré-Congresso

2:) Cong̣resso (realização)

3:) Pós-Congresso.

O primeiro periodo foi dedicado à seleção do pessoal, material, correspondência, organização da agenda, publicação dos Boletins de propaganda, recebimento dos trabalhos, sua tradução, revisão, interpretação e distribuição, organização do corpo técnico de taquígrafos, assessôres, tradutores, revisores, interpretação simultânea, envio de comunicações, solenidades, homenagens, etc. 
Cêrca de 800 cartas foram expedidas nessa fase dos trabalhos (nos quatro idiomas oficiais do Congresso), além de numerosa correspondência recebida, catalogada e arquivada.

Foram apresentadas 50 teses, traduzidas também para os quatro idiomas e impressas para distribuição aos Senhores Congressistas, além de 13 outros trabalhos diversos.

O planejamento da recepção, instalação, realização do Congresso e homenagens aos ilustres visitantes exigiu grande esfôrço e dedicação, e o resultado finalmente obtido só logrou tornar -se efetivo graças à colaboração e boa vontade do grupo que integrou a Secretaria Executiva.

O 2 período constituiu a fase culminante, com a chegada dos Delegados estrangeiros e o pleno funcionamento do Congresso, nada lhe havendo empanado o brilho, desde a sua instalação solene na Câmara dos Deputados - homenagem reciproca do Poder Legislativo e desta Côrte de Contas - com a presença do mais altc magistrado da Nação, até sua fase final.

Para uma idéia mais exata do que foram os trabalhos levados a efeito durante o Congresso pròpriamente dito, será interessante notar que os documentos, impressos e mimeografados, em cada idioma, alcançaram o total de 104 , tendo sido dactilografados, conferidos e mimeografados 935 stencils. Total da tiragem 112 mil.

Para cada Relator foram destinados um ou dois assessôres, alguns sendo servidores do Tribunal e cutros convidados especialmente para êsse trabalho.

Foram publicados diàriamente Boletins, informando os acontecimentos programados ou modificações nêles ocorridas.

O 3 : periodo teve início logo após o encerramento do Congresso e se dedicou exclusivamentè à confecção dos Anais.

Tratou-se, então, da reconstitutição das Notas Taquigráficas, procurando-se conservar, tanto quanto possívei, o estilo e a exatidão dos têrmos empregados pelos oradores.

Após a reconstituição dessas Notas, revisão e dactilografia, foi elaborada a Ata final, a qual foi remeticia para Havana em julho último.

As conclusões das Comissões Técnicas foram impressas e enviadas em 31 de julho para tôdas as Instituições que participaram do conclave.

Foram contratados revisores das quatro linguas oficiais para encetar a revisão definitiva de todos os trabalhos que iriam figurar nos Anais que ora tenho a satisfação de --. repito — em absoluta prioridade apresentar a V. $\mathrm{Ex}^{\mathrm{a}^{\mathrm{s}}}$.

Também naquela oportunidade foram encaminhadas à tradução as Notas Taquigráficas e alyuns trabalhos que, por terem chegado atrasados, nâc puderam ser antes traduzidos.

Realizaram-se cinco recepçôes oficiais, inclusive uma oferecida pelo Excelentissimo Senhor Presidente da República. 
No dia 7 de maio, en Sessão Plenária, foram aprovadas as conclusões das Comissões Técnicas.

$\mathrm{Na}$ sessão solene de encerramento foi fzita a entrega de diplomas e medalhas a todos os Delegados presentes, quando tivemos oportunidade de usar da palavra, apresentandu despedidas e agradecimentos aos Congressis-tas, falando ainda o Sr. Enbaixador da Áustria, agradecendo, em nome de seu pais, a escolha de Viena para sede do $4^{\circ}$ Congresso, e o Ministro Presidente dêstz Tribunal, encerrando a solenidade.

Tôda essa dinâmica, todos êsses trabalhos, todos êsses fatos, são de conhecimento de quantos, trabalhando nesta Casa, acompanharam o desenrolar do Congresso. Mas sinto-me no dever de realçá-los agora, ao entregar a esta Egrégia Côrte os seus Anais. como preito de justiça aos que comigo colaboraranı sem desfalecimentos e - por que não dizê-lo ? - pela satisfação com que vejo, enfim, ultimada a tarefa que recebi temeroso de não ter fôrças para levar a cabo com o sucesso que pretendia e devia alcançar.

Por êsze motivo, sinto-me no dever de transmitir aos meus ilustres pares $\supset$ testemunho eloqüente daqueles que aqui vieram confiantes na capacidade realizadora dos brasileiros e em especial do Tribunal de Contas do Brasil na organizaçâo do $\hat{j}$ ' Congresso, cujo sucesso justificou plenamente a aclamação de Bruxelas, traduzido nas cartas que passo a ler:

\section{BÉLGICA}

Bruxelas, le 11 september 1959.

Cher Monsieur le Ministre,

Je vous transmets en double exemplaire el discours que j'ai pronuncé

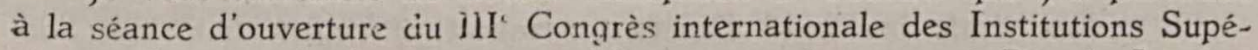
rieures de contrôle des finances publiques qui s'est tenu à Rio de Janeiro.

Je croiyais qu'un examplaire vous en avait été remis à l'époque.

J'y joins lz texte en portugais et en français de l'introduction dans laquelle je me suis adressé plus particulièrement à $\mathrm{M}$. le Président de la République.

Je vous serais bien obligé de remettre mon meilleur souvenir à $\mathrm{M}$. le Président Iyra et croyez bien pour vous même et pour Madame de Freitas, à l'assurance de mes sentiments bien cordiaux.

\section{VRANCKEN}

\section{FRANÇA}

Monsieur le Secrétaire Général,

Paris, le 18 août 1959.

Par lettre du 31 juillet 1959 vous avez bien voulu me faire parvenir trois exemplaires des recommandations approuvées aux Séances Plénières. 
Je vous remer vie vivement de cette transmission ainsi que de l'information selon laquelle la preparation des Annales du Congrès est déjà très avancée.

Nous y voyons un nouveau témoignage des soins exceptionnels dont vous n'aves cessé d'entourer e $3^{\circ}$ Congrès international qui a laissé à chacun d'entre nous un si vivant ei si précieux souvenir.

Veuillez agréer, Monsieur le Secretaire Général, l'espression de mes sentiments les plus distinguées, et de mon souvenir le meilleur.

\title{
ROGER LÉONARD
}

\author{
IRIANDA
}

Baile Atha Cliath

\section{Ministro Presidente}

16th April, 1959.

Tribunal de Contas da União

I desire to present my compliments to your Excellency and to acknowledge with many thanks your Excellency's kind invitation to attend the Third Congress of Supreme Audit Institutions to be held in Rio de Janeiro next month. I very much regret that o owing to pressure of official business I shall be unable to atend the Congress on this particular occasion, but I should be very pleased to receive a copy (in English) of the report of the proceedings.

I enclose draft for $\$ 10$ Dolars in respect of registration fee, and wish to convey to you my best wishes for the success of the Congress.

\author{
W. J. KIELY \\ Comptroller and Auditor General \\ of Ireland
}

\section{PORTUGAL}

Meu caro Dr. Rogério De Freitas:

Lisboa, 21 de maio de 1959.

De regresso a Portugal, apresso-me a agradecer-lhe mais uma vez tôdas as atenções e gentilezas com que sc dignou homenagear-me durante a minha curta estada na capital dêsse grande e maravilhoso país que é o Brasil, de entre os quais destaco o honroso convite que muito me sensibilizou para o magnifico jantar que no passado dia 3 se realizou na vossa atraente e encantadora residência, onde o meu Prezado Amigo e sua Gentil Senhora receberam com a maior amabilidade e cortesia tôdas as pessoas 
que tiveram a felicidade de particıpar em tão agradável recepção, que ao mesmo tempo lhes proporcionou o ensejo de apreciarem alguns dos mais excelentes pratos da saborosa cozinha brasileira.

Quanto aos seus pedidos tomei boa nota dêles e serão satisfeitos logo que me seja possivel.

Aproveito a oportunidade para lhe enviar uma nota de erratas coni relação an trabalho do Conselheiro CELSO LousAda intitulado "Responsabilidades Financeiras - Subsidios para um estudo" da qual eu havia já entregado na Secretaria do Congresso 100 exemplares antes da distribuição do raferido trabalho, mās que, naturalmente por falta de tempo, não puderam ser incluidas nas respectivas publicações. Porém, como os meus Amigos vão tratar brevemente da publicação dos "Anais", espero que nessa altura aquelas sejam consideradas em harmonia com os desejos do autor.

Viva o Brasil! Viva a Comunidade Luso-Brasileira!

Afetuosos cumprimentos para a sua Exma. Espôsa e para si um cordial abraço do

$$
\begin{aligned}
& \text { Amigo mto. grato } \\
& \text { Jõ̃o Bartholomeu Junior }
\end{aligned}
$$

ITÁLIA

Preg.mo Ministro,

Roma, 29 maggio 1959

Invis, all'Eccimo Presidente PEREIRA LIRA l'espressione del nostro animammirato, memore e grato.

A Lei, che è stato preposto all'organizzazione del Congresso ed ha visto coronata la Sua opra infaticabile e sapiente da un successo veramente lusinghiero, desidero aggiungere le particolari felicitazioni mie e del mio collega dott. Vigliar.

La prego di porgere i nostri omaggi alla Sua eletta Signota ed i nostri migliori saluti al gentile Ministre Coutinho, agli altri componenti del Tribunale dei conti.

M'abbia con molte cordialitá

\section{Giovanni Amatucci}

\section{D.LEMANHA}

Your Excellency.

Frankfurt, 11 June de 1959.

In my letter of even dare addressed to His Excellency, Senhor MinistroPresidente José Perziaa Lira, I have casressed my thanks for the cordial reception of anc' care cxiended ao Ministeriäirat Dr. Dressler representang 
me at the 3rd International Congress of Suprame Audit Institutions in Rio de Janeiro.

May I also beg ynur Excellency tc accept my sincerest thanks and those of Dr. Dressler, who is ansious to thank you again for the friendliness and hospitality bestowed upon him in your beautiful country. May I also heartily congratulate Your Excellency on the outestanding success of the Congress in which I could, unfortunately, not tak epart.

I beg Your Excellency to accept the renowed assurance of my highest consideration.

Dr. HERTEL.

\section{BÉrGICA}

Bruxelles, le 4 juin 1959.

Mon cher Ministre :

Rentié definitivement à Bruxelles in m'est très agreable de vous adresser les remerciements de la délégation belge au Congrès de Rio de Janeiro pour toutes les amabilités que vous lu avez témoignées au cours des journées de travaux que nour avons passées ensamble. Croyez bien que nous garderons un excellent souvenir de votre gentillesse et de celle de Madame de Freitas.

Mais je manquerais à tous mes devoirs d'hospitalité si je n'y ajoutais pas mas félicitations les plus sincères et les plus vives à celui qui fut la veritable cheville ouvrière du Congrès. Il vous a causé bien des soucis, il vous a donné bien du travail; vous riy avez pas ménagé vos peines ni votre dévouement et le succès incontestable qu il a obtenu vous a récompensé certainement des difficultés cute vous avez eues à surmonter et du courage que vous avez parfois eu à déployer.

J'ai commencé à revoir les textes français des rapporte qui ont été traduits et je vous les transmettrai dès que ce travail de revision sera terminé. Par ailleurs, d'ici quelque temps, je vous enverrai une copie du quastionnaire que je me propose d'adresser aux institutions supérizures de contrôle de l'Europe, à l'effet d'abord de les grouper selon le voeu du Congrès et ensuite d'obtenir urie documentation la plus complète possibla sur leur organisation et leur fonctionnement. Nous pourrions ainsi commencer le travail de collaboration que nous avions envisagé dans nos entretiens à Rio

Je vais égalemente me mettre en rapport avec les services cinopetents de l'organisation des Nations-Unies à New York, afin d'examiner les moyens les meilleurs d'y intégrer nos organisations nationales et d'être utile ainsi aux pays jeunes. Ce serait réaliser de cette manière les bouts que nous proposions par la création du Conseil international. 
Je na voudrais pas terminer ma lettre sans vous signaler l'accueil charmant que, grâce à votre aimable intervention, nous avons reçu aux escales des Tribunaux de Bahia et de Recife, qui nous ont permis de parcourir très rapidement ces villes si intéressantes du Brésil. Veuillez croire, mon cher Ministre, à l'assurance de mes sentiments bien cordiaux.

VRANCKEN. 